\title{
ESTUDOS DA DEPOSIÇÃO ÁCIDA EM DOIS PONTOS DE MONITORAMENTO NA CIDADE DE LIMEIRA.
}

\author{
Eduardo H. Martins (IC), Simone A. Pozza (Orientadora)
}

\begin{abstract}
Resumo
O presente estudo tem como objetivo o monitoramento descontínuo de precipitação ácida em dois locais (Campus I e Campus II da Unicamp em Limeira), usando amostradores simples de coleta. Em ambos os pontos houve similaridades entre os resultados $(\mathrm{pH}>5)$, porém observou-se uma pequena interferência por excreta de pássaros que alterou significativamente uma das amostras coletada em Campus II da Unicamp.
\end{abstract}

Palavras Chave: Chuva ácida, Poluição Atmosférica, Deposição Úmida.

\section{Introdução}

A chuva ácida é consequência da má qualidade do ar e influencia na acidificação do ambiente. Os problemas ambientais e de saúde consequentes direta ou indiretamente do fenômeno ascendeu à necessidade de abordagem do tema. Após estudo de Martins (2014) ${ }^{1}$, realizado no Campus I da Unicamp em Limeira, houve a proposta de continuidade e expansão do estudo visando agora o monitoramento de chuva ácida em outro local, simultaneamente. Os pontos de monitoramento foram a Estação Meteorológica da Faculdade de Tecnologia (Campus I) e a Faculdade de Ciência Aplicadas (Campus II)

\section{Resultados e Discussão}

O período amostragem (24 amostras) compreendeu-se entre setembro de 2014 a novembro de 2014. O protocolo de coleta consistiu em amostragens realizadas a cada $24 \mathrm{~h}$, caso houvesse ocorrência da precipitação, utilizando um coletor pluviômetro (Figura 1) ${ }^{2}$.

Figura 1. Coletor pluviômetro no Campus I.

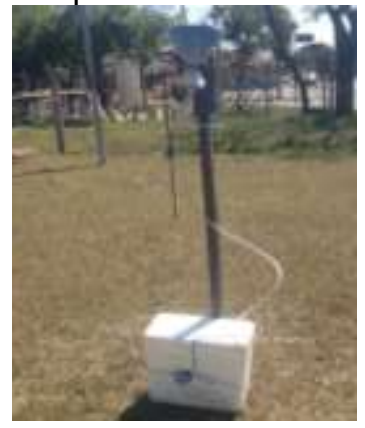

Após coleta, mediu-se o pH das amostras. $\mathrm{Na}$ Tabela 1 estão apresentados os resultados de $\mathrm{pH}$ mínimo, máximo e Média Ponderada pelo Volume (MPV) nos dois pontos de monitoramento, comparando com os resultados do estudo anterior, realizado apenas no Campus I por Martins (2014) ${ }^{1}$.

Tabela 1. Comparativo dos valores de $\mathrm{pH}$ medidos no estudo de Martins (2014) ${ }^{1}$ e no estudo atual.

\begin{tabular}{|l|c|c|c|c|c|c|}
\hline & \multicolumn{2}{|c|}{ Campus I } & \multicolumn{2}{c|}{ Campus II } & \multicolumn{2}{c|}{$\begin{array}{c}\text { Campus I (Martins, } \\
\text { 2014) }\end{array}$} \\
\hline & $\mathbf{H}^{+}$ & $\mathbf{p H}$ & $\mathbf{H}^{+}$ & $\mathbf{p H}$ & $\mathbf{H}^{+}$ & $\mathbf{p H}$ \\
\hline Máximo & 2,34 & 5,63 & 8,70 & 5,06 & 10,00 & 5,00 \\
\hline Mínimo & 0,08 & 7,10 & 0,07 & 7,15 & 0,13 & 6,89 \\
\hline MPV & 0,76 & $\mathbf{6 , 1 2}$ & 1,65 & $\mathbf{5 , 7 8}$ & 2,00 & 5,6 \\
\hline
\end{tabular}

Verificou-se que, no ponto de monitoramento, localizado em Campus II, o pH foi mais ácido comparado ao Campus I. Isto devido à presença de interferentes na amostra. Um dos interferentes observado constantemente foi excreção de pássaros, o que pode ter causado maior acidez ${ }^{3}$.

\section{Conclusões}

Concluiu-se que não houve, em ambos os pontos, ocorrência do fenômeno da precipitação ácida, ou seja, MPV < 5, segundo valor de referência para chuvas naturais ${ }^{3}$.

\section{Agradecimentos}

Ao Gilberto de Almeida, à Nathalia Morgana, à Rita Cardozo e ao CNPq.

\footnotetext{
${ }^{1}$ Martins E. H. 2014 Verificação de acidez e quantificação química de sulfato e nitrato em precipitações. UNICAMP. Iniciação Científica.

${ }^{2}$ Mortatti, J. 1995 Erosão na Amazônia: processos, modelos e balanços. Tese (Livre Docência). Universidade de São Paulo. Piracicaba.

${ }^{3}$ Fornaro, A. (2006) Águas de chuva: conceitos e breve histórico. Há chuva ácida no Brasil? Revista USP. São Paulo n.70, pp. 78-87.
} 